\title{
Level of von Willebrand factor to assess the occurrence and prognosis of acute myocardial infarction
}

\author{
Nannan Wu, Yunxiang Chen, Min Hou \\ Clinical Laboratory, Tianjin Chest Hospital, Tianjin, China \\ Contributions: (I) Conception and design: N Wu; (II) Administrative support: M Hou; (III) Provision of study materials or patients: N Wu; (IV) \\ Collection and assembly of data: Y Chen; (V) Data analysis and interpretation: N Wu; (VI) Manuscript writing: All authors; (VII) Final approval of \\ manuscript: All authors. \\ Correspondence to: Min Hou. Clinical Laboratory, Tianjin Chest Hospital, Tianjin 300222, China. Email: houmin6997@sina.com.
}

\begin{abstract}
Background: To observe and compare the differences in von Willebrand factor antigen (vWF:Ag) levels between patients with acute myocardial infarction (AMI) and healthy residents, and to determine whether this measure can be used to evaluate the incidence of AMI and whether or not to undertake cardiac bypass surgery.

Methods: A retrospective analysis was conducted using the clinical data of 110 patients with acute cardiovascular disease without bypass (no bypass group), 351 patients with AMI and bypass (bypass group), and 60 healthy volunteers (healthy group) who underwent physical examination between July 2018 and May 2019 in Tianjin Chest Hospital. The plasma vWF:Ag was measured and the receiver operating characteristic (ROC) curve was utilized to critically assess its efficacy in determining the occurrence and prognosis of $\mathrm{AMI}$, and the Chi-square test was used to evaluate the correlation between vWF:Ag and clinicopathological factors.

Results: The plasma vWF:Ag was 201\% (139\%, 250\%) in the bypass group, $118 \%$ (107\%, 134\%) in the non-bypass group, and $95.5 \%(85.25 \%, 102.75 \%)$ in the control group, and the differences were statistically significant $(\mathrm{P}<0.05)$. The component status of the plasma vWF:Ag used in the bypass group was greater as compared to that of the normal group $(\mathrm{P}<0.05)$ and the non-bypass group $(\mathrm{P}<0.05)$. The area under the ROC curve of plasma vWF:Ag level was 0.797 (95\% CI: 0.749-0.845). When the medical decision level of plasma vWF:Ag was set at $155.5 \%$, the sensitivity and specificity of predicting AMI were $68.9 \%$ and $86.7 \%$, respectively. The levels of plasma $\mathrm{vWF}: \mathrm{Ag}$ in patients with $\mathrm{AMI}$ were correlated with hypertension, diabetes, age, and history of cerebral infarction $(\mathrm{P}<0.05)$.
\end{abstract}

Conclusions: The plasma vWF level can predict the occurrence of AMI and provides guidance for cardiac bypass surgery.

Keywords: Von Willebrand factor (vWF); acute myocardial infarction (AMI); biomarkers

Submitted Jul 22, 2021. Accepted for publication Sep 18, 2021.

doi: 10.21037/apm-21-2162

View this article at: https://dx.doi.org/10.21037/apm-21-2162

\section{Introduction}

Acute myocardial infarction (AMI) involves extensive myocardial necrosis caused by acute and sustained coronary ischemia and hypoxia, with characteristic changes due to the occluded duration and reperfusion time, the degree of occlusion, and the chance of collateral circulation (1). Clinically, patients with AMI are subject to persistent retrosternal pain, progressive electrocardiographic changes, elevated serum markers of myocardial necrosis, and other characteristic changes $(2,3)$. As a disease with high morbidity and mortality rates worldwide, AMI seriously threatens the health and safety of a large population in China (4-8). Currently, c Tn has been regarded as the clinical "gold standard" for the diagnosis of AMI. However, due to its low 
specificity, cTn may elevate in chronic renal insufficiency, stroke, heart failure, severe infections, cachexia, and other diseases (9-11), which can complicate a specific diagnosis. With the update of detection techniques, the potential for von Willebrand factor antigen ( $\mathrm{vWF}: \mathrm{Ag}$ ) to play a role in the diagnosis of AMI (12) has been increasingly recognized, due to it participating in the inflammatory response to myocardial ischemia-reperfusion injury and promoting complement activation to exacerbate ischemia-reperfusion injury (13-15).

von Willebrand factor ( $\mathrm{vWF}$ ) is known as a large adhesive and multimeric glycoprotein that is incorporated within the vascular endothelial cells, and is encrypted on a portion of chromosome 12 . A $250-\mathrm{kDa}$ protein which builds up monomers is encoded by the $\mathrm{vWF}$ gene. Upon reaching its maturity stage, a molecule will then consist of 50 to 100 monomers that can develop a size up to $20 \mathrm{MDa}$. vWF subunits contains binding sites for the following elements: factor VIII, platelet glycoprotein $\mathrm{Ib}$ (GPIb), GPIIb/IIIa, heparin, and collagen, in which some are reliant to shear-induced conformational change (16) that is active in blood plasma and essential in the course of thrombosis (17). It is being kept in the a-granules of platelets and the Weibel-Palade bodies of endothelial cells, as represented by an ultra-large vWF (UL-vWF). Substances such as metalloprotease with thrombospondin type 1 repeats, member 13 (ADAMTS13), and a disintegrin transform UL-vWF into inert, smaller pieces (18). A damaged vessel membrane may lead to an extreme shear stress, which can instigate $\mathrm{vWF}$ to concurrently merge with the platelet receptor GPIB-IX-V complex (via A1 domain) and the endothelial collagen (via A1 and A3 domain). For this reason, $\mathrm{vWF}$ plays an important role in creating a bond between the platelets and subendothelial matrix.

According to the past researches, patients with AMI who received greater contents of $\mathrm{vWF}: \mathrm{Ag}$, and persisted for 1 week after reperfusion therapy (19) but also had a definite increase of UL-vWF multimers (20). Subsequently, they indicated that coronary plaque burden is actually connected with the vWF:Ag levels in patients who have stable angina pectoris, while plasma levels of $\mathrm{vWF}$ were remarkably higher in patients with angiographic no-reflow, excluding those with electrocardiographic no-reflow (21).

In addition, these analyses predominantly paid attention on the probability of occurrence and prognosis value of plasma vWF and AMI. However, the efficiency of using this parameter to predict the occurrence of AMI, and the difference of the vWF levels between AMI patients who underwent bypass surgery and those who didn't remains unclear. We present the following article in accordance with the STARD reporting checklist (available at https://dx.doi. org/10.21037/apm-21-2162).

\section{Methods}

\section{Participants}

The participants in this study were 60 healthy volunteers (healthy group) and $461 \mathrm{AMI}$ patients receiving coronary angiography (CAG) in the Tianjin Chest Hospital between July 2018 and May 2019. Participants were divided into two groups based on whether they underwent bypass surgery, comprising a no bypass group $(\mathrm{n}=110)$ and bypass group $(\mathrm{n}=351)$. All enrolled individuals had imaging data and were not treated with anticoagulants, and the gender, age, imaging results, stent status, and $\mathrm{vWF}$ results of both groups were recorded separately. AMI patients were diagnosed in accordance with the global definition of myocardial infarction [2018], along with clinical evidence.

\section{Specimen collection}

Two $\mathrm{mL}$ of fasting blood was collected in the early morning with $0.105 \mathrm{~mol} / \mathrm{L}$ vacuum blood collection tubes with sodium citrate anticoagulant, which was centrifuged at 3,000 $\times \mathrm{g}$ for 15 min within 2 hours, and the upper layer platelet-poor plasma immediately frozen at $-20{ }^{\circ} \mathrm{C}$ until testing. All the patients attended the study voluntarily. The study was conducted in accordance with the Declaration of Helsinki (as revised in 2013). Patients and their families signed informed consent documents. The study was approved by the ethics committee of Tianjin Chest Hospital.

\section{Main instruments and reagents}

These were a Stago automated coagulation analyzer (Stago) test kit, and a vWF:Ag test kit (nephelometry).

\section{Assay method}

The frozen specimen was re-dissolved at room temperature and then placed on the Stago analyzer for the determination 
Table 1 Basic clinical data

\begin{tabular}{lll}
\hline Groups & Age & Male/female \\
\hline No bypass group $(n=110)$ & $60.93 \pm 12.31$ & $56 / 54$ \\
By pass group $(n=351)$ & $60.84 \pm 10.76$ & $218 / 133$ \\
Healthy group $(n=60)$ & $60.03 \pm 11.11$ & $30 / 30$ \\
$P$ & $>0.05$ & $>0.05$ \\
\hline
\end{tabular}

Table 2 Comparison of plasma vWF:Ag level between bypass, no bypass, and healthy groups

\begin{tabular}{ll}
\hline Groups & vWF \\
\hline Bypass & $201 \%(139 \%, 250 \%)^{\mathrm{a}, \mathrm{b}}$ \\
No bypass & $118 \%(107 \%, 134 \%)$ \\
Healthy & $95.5 \%(85.25 \%, 102.75 \%)$
\end{tabular}

In comparison to the healthy group, ${ }^{a}, \mathrm{P}<0.05$; in comparison to the no-bypass group, ${ }^{\mathrm{b}}, \mathrm{P}<0.05$; no bypass group in contrary to the healthy group, $\mathrm{P}>0.05$.

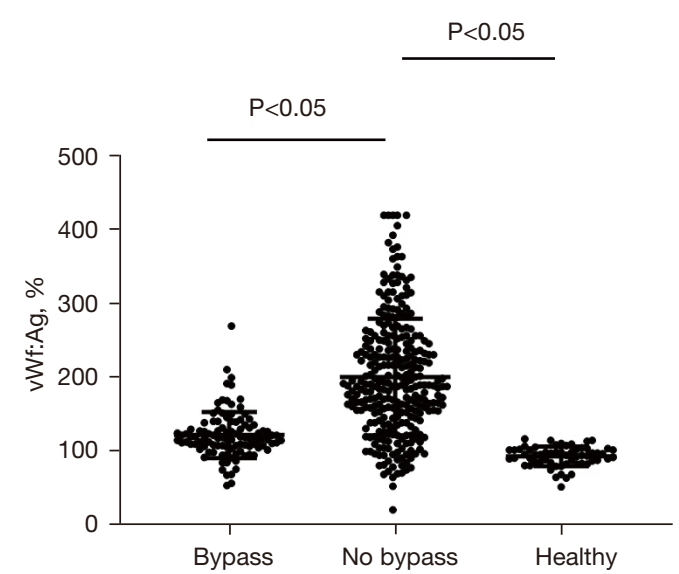

Figure 1 Comparison of plasma vWF:Ag level among three groups. vWF:Ag, von Willebrand factor antigen.

of $\mathrm{vWF}: \mathrm{Ag}$.

\section{Statistical analysis}

VSPSS 22.0 was used for statistical analysis. Data with normal distribution were expressed as mean and standard deviation, and data with normal distribution were expressed as median and interquartile spacing for pairwise comparisons and comparison between groups with the Kruskal Wallis rank sum test between the bypass, no bypass, and control groups, with statistical significance at $\mathrm{P}<0.05$. Pairwise comparisons was conducted among the three groups using Mann-Whitney $U$ test, showing a statistical significance of $\mathrm{P}<0.05$, and receiver operating characteristic (ROC) curve laid out in order to examine the diagnostic performance of $\mathrm{vWF}: \mathrm{Ag}$. Chi-square test was used to evaluate the correlation between vWF:Ag and clinicopathological factors in AMI patients.

\section{Results}

\section{Basic clinical data}

Gender and age between the bypass group and control group were not statistically significant $(\mathrm{P}>0.05)$ but comparable (see Table 1).

\section{Comparison of plasma vWF:Ag level}

The level of plasma vWF:Ag among the bypass group was higher as compared to that of the healthy group and nobypass group, showing a statistical significance $(\mathrm{P}<0.05)$. While, the level of plasma vWF among the no-bypass group was significantly higher than the healthy group, showing no statistical significance $(\mathrm{P}>0.05)$ (see Table 2 and Figure 1).

\section{Performance of plasma vWF:Ag levels in AMI}

The performance of plasma $\mathrm{VWF}: \mathrm{Ag}$ levels in the AMI diagnosis was evaluated by the ROC curve with the bypass group being the positive case and no bypass group being the negative case, and the area under ROC curve of plasma vWF:Ag level was 0.797 (95\% CI: 0.749-0.845) as shown in Figure 2.

Correlation between the levels of plasma vWF:Ag of AMI patients and clinicopathological factors

The levels of plasma vWF:Ag in AMI patients correlated with hypertension, diabetes, age, and a history of cerebral infarction but not gender $(\mathrm{P}<0.05)$, as shown in Table 3 .

\section{Discussion}

First discovered by Erik Avon Willebrane in 1926, vWF is a polysaccharide protein synthesized mainly by endothelial cells and plays a key role in regulating impaired platelet adhesion to endothelia. Endothelial cell damage is the 
causative factor for the development of AMI, and $\mathrm{vWF}$ levels are an important predictor of AMI and an important indicator for assessing its extent of damage, development, and prognosis (15).

Some clinical prediction scores indicate both shortterm and long-term risks such as recurrent ischemic

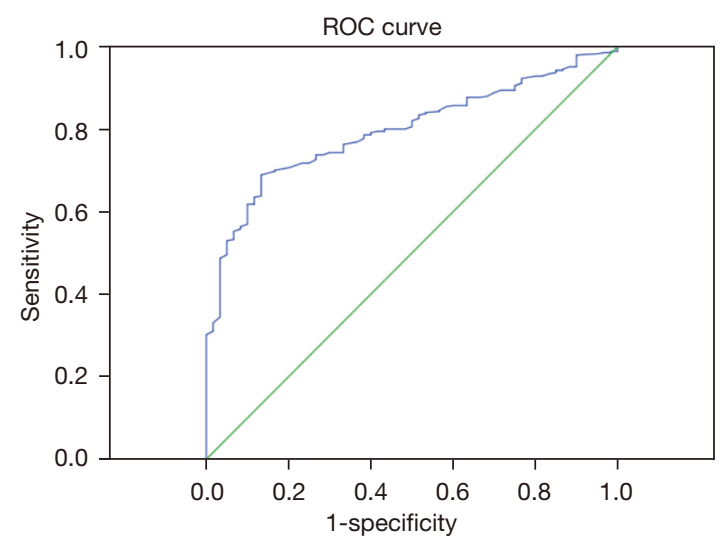

Figure 2 ROC curve of plasma vWF:Ag levels in the diagnosis of AMI. ROC, receiver operating characteristic curve; $\mathrm{vWF}: \mathrm{Ag}$, von Willebrand factor antigen; AMI, acute myocardial infarction. events and death subsequent to myocardial infarction. In comparison, the TIMI risk score is the most convenient type, yet GRACE is reported to be more precise, extensive, and applicable to both NSTEMI and STEMI. Moreover, some biomarkers, including C-reactive protein and B-type natriuretic peptide, can contribute in assigning and classifying patients to a particular risk status. Although, these biomarkers must still be improved and integrated into strategy-based researches. Further, cTn is the only current guideline-approved treatment pathway as seen on any biomarker (22). A substantial relationship between $\mathrm{vWF}$ levels and the possible occurrence of $\mathrm{MI}$ in vascular disease patients is formed. vWF is commonly degraded by the enzymes ADAMTS13-proteolytically speaking. With that, ADAMTS13 activity is reckoned to be abnormal in relation to ischemic cardiovascular disease. In the context of ACS, it is still indeterminate what the real role of this $\mathrm{vWF}$ cleaving protease is. ADAMTS13 levels were apparently minimized in patients with AMI (23). However, some published casecontrol study showed a significant increase of MI risk in those patients who have higher ADAMTS-13 levels (24). This inconsistency is still unexplained and deserves a supplemental analysis. As reported and seen on ST-elevation

Table 3 Analysis of the correlation between the levels of plasma vWF:Ag of AMI patients and clinicopathological factors

\begin{tabular}{|c|c|c|c|c|c|}
\hline Clinicopathological factors & $\mathrm{N}$ & \multicolumn{2}{|c|}{ Levels of plasma vWF:Ag } & Chi-square value & $P$ value \\
\hline High blood pressure & & & & 50.175 & $<0.01$ \\
\hline No & 131 & 37 & 94 & & \\
\hline Yes & 220 & 148 & 72 & & \\
\hline No & 143 & 75 & 68 & & \\
\hline Yes & 208 & 134 & 74 & & \\
\hline Age & & & & 1.513 & $<0.05$ \\
\hline$\geq 65$ & 149 & 41 & 108 & & \\
\hline Male & 263 & 83 & 180 & & \\
\hline Female & 88 & 26 & 62 & & \\
\hline Cerebral infarction & & & & 7.231 & $<0.01$ \\
\hline No & 275 & 95 & 180 & & \\
\hline Yes & 76 & 14 & 62 & & \\
\hline
\end{tabular}


MI (STEMI), vWF levels tend to increase within 24 hours, and make its peak in between 48 to 72 hours before it comes back to the baseline some time around day 14 (25).

In this study, the plasma vWF:Ag level among the bypass group was higher as compared to the no-bypass group, and the level in no-bypass group was higher than the control group, showing no statistical significance $(\mathrm{P}>0.05)$. While the level of plasma vWF:Ag in our study showed no correlation with the number of bypasses and location of coronary artery stenosis, some studies have found it correlated with atherosclerotic plaques (6), and could sensitively reflect the damage status of vascular endothelial cells in patients with atrial fibrillation (13). The risk of atheroembolic events $(3,4)$ and stroke in patients with new onset atrial fibrillation (26) has also been shown to increase dramatically when vWF levels remain elevated in patients with coronary artery disease after treatment. Patients with coronary artery disease and elevated vWF levels should have their hospitalization periods prolonged, and further imaging should be performed to examine the degree of obstruction.

In the current study, we found that the area under the ROC curve of plasma vWF:Ag level evaluating the incidence of AMI exceeded 0.7, indicating the diagnosis and prediction value of $\mathrm{vWF}: \mathrm{Ag}$ factor in AMI. The levels of plasma vWF:Ag can well predict the occurrence of AMI and can sensitively reflect the damage status of vascular endothelial cells in AMI patients, providing an important clinical resource for cardiac bypass surgery.

\section{Acknowledgments}

Funding: None.

\section{Footnote}

Reporting Checklist: The authors have completed the STARD reporting checklist. Available at https://dx.doi. org/10.21037/apm-21-2162

Data Sharing Statement: Available at https://dx.doi. org/10.21037/apm-21-2162

Conflicts of Interest: All authors have completed the ICMJE uniform disclosure form (available at https://dx.doi. org/10.21037/apm-21-2162). The authors have no conflicts of interest to declare.

Ethical Statement: The authors are accountable for all aspects of the work in ensuring that questions related to the accuracy or integrity of any part of the work are appropriately investigated and resolved. The study was conducted in accordance with the Declaration of Helsinki (as revised in 2013). The study was approved by the ethics committee of Tianjin Chest Hospital. All the patients attended the study voluntarily. Patients and their families signed informed consent documents.

Open Access Statement: This is an Open Access article distributed in accordance with the Creative Commons Attribution-NonCommercial-NoDerivs 4.0 International License (CC BY-NC-ND 4.0), which permits the noncommercial replication and distribution of the article with the strict proviso that no changes or edits are made and the original work is properly cited (including links to both the formal publication through the relevant DOI and the license). See: https://creativecommons.org/licenses/by-nc-nd/4.0/.

\section{References}

1. Burke AP, Virmani R. Pathophysiology of acute myocardial infarction. Med Clin North Am 2007;91:553-72; ix.

2. Gao RL. Guideline for diagnosis and treatment of acute myocardial infarction. Chinese Journal of Cardiology 2001;29:710-25.

3. Li P. Observation, prevention and nursing measures of premonitory symptoms of acute myocardial infarction. China Hwalth Care \& Nutrition 2014;(5):3043.

4. He XQ, Liu ML. Prevention and control strategy of coronary heart disease in China. Chinese General Practice 2015;(2):239-40.

5. Hu DY. Advanced course of cardiovascular internal medicine. Beijing: People's Military Surgeon, 2009.

6. Rumana N, Kita Y, Turin TC, et al. Trend of increase in the incidence of acute myocardial infarction in a Japanese population: Takashima AMI Registry, 1990-2001. Am J Epidemiol 2008;167:1358-64.

7. Katzenellenbogen JM, Sanfilippo FM, Hobbs MS, et al. Incidence of and case fatality following acute myocardial infarction in Aboriginal and non-Aboriginal Western Australians (2000-2004): a linked data study. Heart Lung Circ 2010;19:717-25.

8. Wang $\mathrm{W}$, Zhu ML, Wang YJ, et al. Cardiovascular disease, a emerging public health issue in China. Summary of China cardiovascular disease report 2011. Chinese Circulation Journal 2012;27:409-11.

9. Abbas NA, John RI, Webb MC, et al. Cardiac troponins 
and renal function in nondialysis patients with chronic kidney disease. Clin Chem 2005;51:2059-66.

10. Finsterer J, Stöllberger C, Krugluger W. Cardiac and noncardiac, particularly neuromuscular, disease with troponin-T positivity. Neth J Med 2007;65:289-95.

11. Mozaffarian D, Benjamin EJ, Go AS, et al. Heart disease and stroke statistics--2015 update: a report from the American Heart Association. Circulation 2015;131:e29322. Erratum in: Circulation 2015;131:e535. Erratum in: Circulation 2016;133:e417.

12. Qu L, Jiang M, Qiu W, et al. Assessment of the diagnostic value of plasma levels, activities, and their ratios of von Willebrand factor and ADAMTS13 in patients with cerebral infarction. Clin Appl Thromb Hemost 2016;22:252-9.

13. Agewall S, Giannitsis E, Jernberg T, et al. Troponin elevation in coronary vs. non-coronary disease. Eur Heart J 2011;32:404-11.

14. Su Y, Wang L, Zhang MZ. Progress in epidemiological study of acute myocardial infarction. Chinese Journal of Integrative Medicine on Cardio/Cerebrovascular Disease 2012;10:467-9.

15. Wang WZ, Qi HG, Gao X, et al. The effect of soluble CD14-st on the assessment and prognosis of patients with acute paraquat poisoning. Chinese Journal of Emergency Medicine 2016;25:1159-65.

16. Spiel AO, Gilbert JC, Jilma B. von Willebrand factor in cardiovascular disease: focus on acute coronary syndromes. Circulation 2008;117:1449-59.

17. Shahidi M. Thrombosis and von Willebrand Factor. Adv Exp Med Biol 2017;906:285-306.

18. Zheng XL. Structure-function and regulation of

Cite this article as: $\mathrm{Wu} \mathrm{N}$, Chen Y, Hou M. Level of von Willebrand factor to assess the occurrence and prognosis of acute myocardial infarction. Ann Palliat Med 2021;10(10):1044410449. doi: 10.21037/apm-21-2162
ADAMTS-13 protease. J Thromb Haemost 2013;11 Suppl 1:11-23.

19. Wang X, Zhao J, Zhang Y, et al. Kinetics of plasma von Willebrand factor in acute myocardial infarction patients: a meta-analysis. Oncotarget 2017;8:90371-9.

20. Yan B, Xu M, Zhao Y, et al. Development of a novel flow cytometric immunobead array to quantify VWF: Ag and VWF: GPIbR and its application in acute myocardial infarction. Eur J Haematol 2017;99:207-15.

21. Sgueglia GA, Niccoli G, Spaziani C, et al. Baseline von Willebrand factor plasma levels and no-reflow phenomenon after primary percutaneous coronary intervention for ST segment elevation myocardial infarction. Int J Cardiol 2010;145:230-2.

22. Reed GW, Rossi JE, Cannon CP. Acute myocardial infarction. Lancet 2017;389:197-210.

23. Kaikita K, Soejima K, Matsukawa M, et al. Reduced von Willebrand factor-cleaving protease (ADAMTS13) activity in acute myocardial infarction. J Thromb Haemost 2006;4:2490-3.

24. Chion CK, Doggen CJ, Crawley JT, et al. ADAMTS13 and von Willebrand factor and the risk of myocardial infarction in men. Blood 2007;109:1998-2000.

25. Sakai H, Goto S, Kim JY, et al. Plasma concentration of von Willebrand factor in acute myocardial infarction. Thromb Haemost 2000;84:204-9.

26. Ren J, Li G, Men JL. Von Willebrand factor in evaluating stroke risk of patients with new-onset atrial fibrillation after elective percutaneous coronary intervention. Chinese Journal of Clinical Laboratory Science 2017;35:925-9.

(English Language Editor: B. Draper) 